\title{
Estudo eletroforético sobre a estrutura populacional do krill, Euphausia superba Dana, na região da Passagem Drake- Estreito de Bransfield - oeste da Peninsula Antártica
}

\author{
PHAN Van Ngan ${ }^{1}$; Vicente GOMES ${ }^{1}$; Maria José de Arruda Campos Rocha PASsO ${ }^{1}$ \& Hana SUZUKI ${ }^{2}$ \\ 1 - Instituto Oceanográfico da Universidade de São Paulo \\ (Caixa Postal 9075, 01065-970, São Paulo, SP, Brasil) \\ 2 - Centro de Estudos do Mar, Universidade Federal do Paraná \\ (Caixa Postal 43, 83200-970, Paranaguá, PR, Brasil)
}

- Abstract: Samples of Antarctic krill, Euphausia superba, collected from 18 locations in the Drake Passage, Bransfield Strait and on the west coast of the Antarctic Peninsula were analyzed for protein variation using enzyme electrophoresis. Of 19 enzyme loci studied, $14(73,6 \%)$ exhibit allelic variations. Average heterozigosity for a station varies from 0,129 to 0,157 . Five loci are with null alleles. Differences in allelic frequency related to sex and size of animal were not observed. No significant deviations from random mating expectation according to the Hardy-Weinberg principle were found in any locus at any station except Aph- 1 at the stations 8 and 18; Est-1 at the station 9 and 11, and Mdh-1 at the station 18. These deviations are likely due to the difficulty in analysing the enzyme pattern or to the small sample sizes. Analysis of allele distribution indicate that samples from all locations are homogeneous in all polymorphic loci. Genetic distances between samples vary from 0.000 to 0.002 . These results suggest that specimens from all locations of the investigated region belong to a single genetically homogeneous population. The contribution of physical and biological factors to the homogeneity of krill in the region and the necessity of a detailed study utilizing not only electrophoresis but also another techniques were discussed.

- Resumo: Foram analisadas amostras de krill, Euphausia superba, coletadas em 18 estaçōes na regiāo da Passagem Drake-Estreito de Bransfield-oeste da Península Antártica para estudar as variaçōes genéticas através de eletroforese de enzimas em gel de poliacrilamida. Dezenove loci enzimáticos foram analisados, dos quais quatorze $(73,6 \%)$ apresentam variaçōes alélicas. Cinco dos loci polimórficos apresentam alelos nulos. A heterozigosidade média varia de 0,129-0,157 dependendo da localidade. Nāo foram observadas, no entanto, diferenças relacionadas ao sexo e ao tamanho do animal. A conformidade de distribuição de fenótipos em relação ao equilíbrio de Hardy-Weinberg foi encontrada em todos os loci em todas as estaçōes, exceto Aph- 1 das estaçōes 8 e 18, Est-1 das estaçōes 9 e 11 e Mdh-1 da estação 18. As análises de distribuição de alelos indicam a homogeneidade entre todas as amostras coletadas em localidades diferentes. A distância genética entre as amostras varia de $0,000-0,002$. Os resultados sugerem que os indivíduos de todas as amostras coletadas em todas as estaçōes, pertencem a uma única população com acasalamento ao acaso. A contribuição de fatores físicos e biológicos na homogeneidade do krill na regiāo e a necessidade de um estudo mais detalhado, utilizando não somente a eletroforese mas também outros métodos, foram discutidas.

- Descriptors: Population structure, Electrophoresis, Isoenzymes, Euphausia superba, Drake Passage, Bransfield Strait, Antarctic Peninsula, Antarctica.

- Descritores: Estrutura da população, Eletroforese, Isoenzimas, Euphausia superba, Passagem de Drake, Estreito de Bransfield, Península Antártica, Antártica. 


\section{Introdução}

Ocorrem no Oceano Antártico sete espécies da familia Euphausiidae (FAO, 1985) pertencentes a dois gêneros, Euphausia (cinco espécies)e Thysanoessa (duas espécies). Euphausia superba, o krill da Antártica, referido daqui em diante como krill, é a espécie que apresenta o maior tamanho dentre os eufausiáceos do mundo. Seu comprimento total pode chegar até $60 \mathrm{~mm}$. Esta espécie constitui cerca de $50 \%$ da biomassa do zooplâncton no Oceano Antártico. Além de ser o organismo chave entre os produtores primários marinhos e os predadores dos níveis superiores da cadeia alimentar do ecossistema antártico, o krill é considerado como uma espécie de grande potencialidade para a pesca comercial. Em geral, o krill tem distribuiçāo circumpolar ao sul da Convergência Antártica (Marr, 1962). Sua ocorrência, entretanto, não é homogênea ao longo de toda área, apresentando aglomeraçōes espaciais. Em grande escala hidrográfica, existem duas zonas com áreas de alta biomassa de krill. Uma está associada à Deriva do Vento Leste e encontra-se próxima ao Continente Antártico; a outra ocorre onde esta Deriva encontra-se com os vastos sistemas de giros e atua juntamente com a Deriva do Vento Oeste (Priddle et al., 1987). Estas áreas de alta concentração, no entanto, não são isoladas, existindo, entre elas, regiōes de menores densidades. Nesta escala, a distribuiçāo circumpolar do krill está ligada intimamente com a circulação oceânica implicando em certo intercâmbio de genes e na homogeneidade genética da espécie entre as áreas.

Em meso-escala, no entanto, têm sido demonstradas associaçōes entre as grandes concentraçōes de krill e massas de águas especificas, tais como giros ciclônicos (Lubimova et al., 1982). A distribuição confinada do krill, dentro de sistemas de circulações locais, dá origem à especulaçōes de que algumas concentraçōes poderiam constituir populaçōes isoladas ou até mesmo raças distintas (Makarov, 1974). Mackintosh (1973) descreveu cinco áreas principais de alta concentraçāo de krill, denominando estas concentraçōes de estoques de Weddell, de Enderby, de Kerguelen-Gaussberg, do Mar de Ross e do Mar de Bellingshausen. Lubimova et al. (1982) postularam que o krill distribuído nos sistemas circulatórios fechados dos Setores f́ndico e Pacífico constituem populações isoladas.

Outras evidências que levam vários autores a sugerirem a existência de populaçōes discretas e isoladas de krill ao redor do Continente Antártico são as ocorrências de diferentes fenótipos regionais. Mackintosh (1972) e Fevolden (1979) encontraram krill com diferentes taxas de crescimento, estádios de maturidade e épocas de desova nas regiōes norte e sul do Setor Atlântico. McWhinnie et al. (1981, cit. in: Anderson, 1982) relataram diferenças na taxa de respiração e na tolerância à temperatura do krill de diferentes regiöes.

Durante os últimos quinze anos foram realizados vários estudos genéticos de krill através de métodos eletroforéticos (Ayala et al., 1975; Fevolden \& Ayala, 1981; Anderson, 1982; Schneppenheim \& MacDonald, 1984; Fevolden, 1988; Fevolden \& Schneppenheim, 1989). Apesar de existirem evidências de uma só populaçăo circumpolar inter-reprodutiva, há, entretanto, pequenas mas significativas diferenças que ainda não foram esclarecidas, indicando a possível existência de populações isoladas.

O objetivo deste trabalho é o de estudar, através do método eletroforético, a variação genética e a estrutura populacional do krill no Estreito de Bransfield, na Passagem Drake, ao oeste da Península Antártica onde pode existir uma mistura de krill do Mar de Bellingshausen e do Mar de Weddell, duas das regiōes de grande concentração desse animal descritas por Mackintosh (1973) no Oceano Antártico.

\section{Material e métodos}

O material utilizado neste trabalho foi coletado em 18 localidades na região da Passagem Drake - Estreito de Bransfield - oeste da Península Antártica com rede de arrasto de meia água, Isaacs-Kidd, ou com rede Bongô, a bordo do N/Oc."Prof. W. Besnard" do Instituto Oceanográfico, Universidade de São Paulo. As posiçōes das localidades e anos de coleta estão na Figura 1. Imediatamente após a captura, o krill foi colocado sobre papel de filtro durante alguns segundos para retirar o excesso de água e em seguida, foi distribuído em camada única em bandejas de plástico e colocado no congelador a $-20^{\circ} \mathrm{C}$ durante aproximadamente seis horas. Depois deste tratamento, foi colocado em sacos plásticos e conservado na mesma temperatura para ser transportado ao laboratório do Instituto Oceanográfico, em São Paulo. Este tratamento foi necessário para que os animais nāo aderissem uns aos outros durante o congelamento e para facilitar o uso do material congelado. A identificação da espécie foi feita de acordo com as chaves de Mauchline (1982).

Foram estudadas as seguintes enzimas: desidrogenase láctica ( $\mathbf{L d h})$, desidrogenase málica (Mdh), enzima málica (Me), desidrogenase isocitrica (Idh), oxidase aldeídica (Ao), transferase do amino aspartato (Aat), esterases (Est), fosfatase alcalina (Aph) e fosfatase ácida (Acph). Os padrōes de Acph, no entanto, são idênticos aos de Aph, conseqüentemente apenas os padrōes de Aph foram utilizados. 


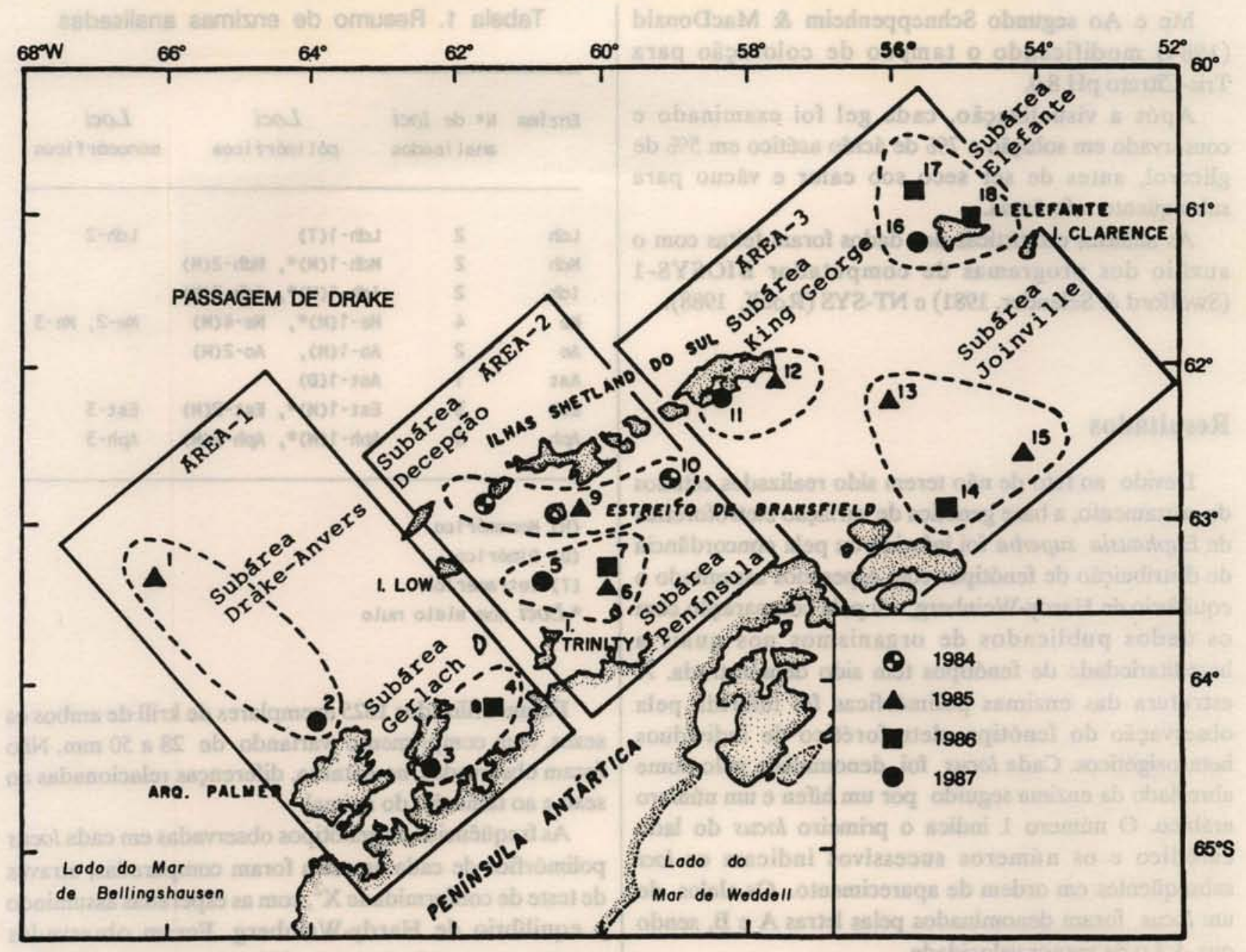

Fig. 1. Posições das estações de coleta e seus agrupamentos em áreas e subáreas.

Os extratos para as enzimas Mdh, Aat, Idh e Acph, foram obtidos através de maceração do abdome com Tris-EDTA-Glicerol (Scopes, 1968); para as enzimas Ldh, Ao, Me, Aph e Est, através de maceraçāo do animal inteiro com a mesma soluçāo de extraçāo. A proporção foi de 1:1 (peso:volume) e a centrifugaçāo foi de $9000 \mathrm{rpm}$ durante 40 min entre $0^{\circ}-5^{\circ} \mathrm{C}$. A quantidade de amostras utilizadas foi de $5 \mu \mathrm{l}$ para Est, Ldh e Mdh, e de $10 \mu \mathrm{l}$ para Aph, Acph, Aat, Ao, Idh e Me.

Foi utilizado método eletroforético vertical em gel de poliacrilamida descrito por Akroyd (1967) e modificado por Phan (1980). Os sistemas de tampão e outras condições para separação eletroforética variaram de acordo com as enzimas:

Ldh, Mdh, Aph, Acph e Est segundo Phan (1980): a análise foi a $45 \mathrm{~mA} / 40 \mathrm{~min}$ para $\mathrm{Mdh}$, Aph e Acph; $120 \mathrm{~min}$ para Ldh e 60 min para Est.

Idh e Me: gel de duas camadas em tampão Tris-Citrato pH 5,8 em diferentes diluiçōes para cada camada; $1 / 2$ para a camada inferior e $1 / 28$ para a camada superior. O tampão da cuba foi o mesmo, com diluição 1/10. A análise foi a 45 $\mathrm{mA} / 50$ min para Idh e $75 \mathrm{~min}$ para Me.

Aat e Ao: gel de duas camadas em tampão Tris-Citrato pH 7,0. Para Ao, o mesmo tampāo foi utilizado como tampāo da cuba e a análise foi a $45 \mathrm{~mA} / 120 \mathrm{~min}$. Para Aat, o tampão da cuba foi Tris-Glicina $\mathrm{pH} 8,9$. A análise foi a $200 \mathrm{~V} / 40 \mathrm{~min}$.

Para a visualização foram empregados reagentes de grau analítico da Sigma. Os métodos de coloraçāo foram os seguintes:

Ldh, Mdh e Aph segundo Fevolden \& Ayala (1981), modificando o tampão de coloração para $0,1 \mathrm{M}$ Tris- $\mathrm{HCl}$ $\mathrm{pH} 8,0$ e o de imersảo de Aph para 0,2M Tris- $\mathrm{HCl}$ pH 9,5.

Acph segundo Fevolden \& Ayala (op. cit.) sendo o tampão de coloração modificado para $0,2 \mathrm{M}$ Acetato $\mathrm{pH}$ 5,0 .

Idh segundo Fevolden \& Ayala (op. cit.) substituindo-se o tampão de coloração por Tris-Citrato $\mathrm{pH} \mathrm{8,0.}$

Aat segundo Schneppenheim \& MacDonald (1984) e Est segundo Flowerdew \& Crisp (1975). 
Me e Ao segundo Schneppenheim \& MacDonald (1984) modificando o tampão de coloração para Tris-Citrato $\mathrm{pH} 8,0$.

Após a visualização, cada gel foi examinado e conservado em soluçāo a 7\% de ácido acético em $5 \%$ de glicerol, antes de ser seco sob calor e vácuo para subseqüente referência.

As análises estatísticas dos dados foram feitas com o auxílio dos programas de computador BIOSYS-1 (Swofford \& Selander, 1981) e NT-SYS (Rohlf, 1988).

\section{Resultados}

Devido ao fato de não terem sido realizados estudos de cruzamento, a base genética de variação eletroforética de Euphausia superba foi inferida ou pela concordância de distribuição de fenótipos com esperados assumindo o equilibrio de Hardy-Weinberg, ou pela comparação com os dados publicados de organismos nos quais a hereditariedade de fenótipos tem sido demonstrada. A estrutura das enzimas polimórficas foi inferida pela observação do fenótipo eletroforético de indivíduos heterozigóticos. Cada locus foi denominado pelo nome abreviado da enzima seguido por um hifen e um número arábico. $\mathrm{O}$ número 1 indica o primeiro locus do lado catódico e os números sucessivos indicam os loci subseqüentes em ordem de aparecimento. Os alelos de um locus foram denominados pelas letras $\mathrm{A}$ e B, sendo que $A$ é o de menor velocidade.

A variaçāo genética de cada amostra foi estimada pela (1) proporção de loci polimórficos (um locus é considerado polimórfico se a freqüência do alelo mais comum não é maior do que 0,95 ); (2) heterozigosidade média de todos os loci e (3) número médio de alelos por locus. Foi encontrada variação alélica em $14(73,6 \%)$ dos 19 loci examinados. Cinco loci, Ldh-2, Me-2, Me-3, Est-3 e Aph-3, foram monomórficos (Tab. 1). As freqüências de alelos nos loci polimórficos e o número de exemplares utilizados na análise de cada locus em cada estação estão na Tabela 2.

A Tabela 3 resume as variaçōes genéticas das amostras de cada estação. A porcentagem de loci polimorficos, variou de $63,2 \%$ a $73,7 \%$ com o valor médio de $69,6 \%$; a heterozigosidade média observada, variou de 0,129 \pm 0,027 a $0,161 \pm 0,030$ com o valor médio de $0,147 \pm 0,011$; a heterozigosidade média esperada assumindo o equilibrio de Hardy-Weinberg variou de 0,128 $\pm 0,028$ a $0,154 \pm 0,030$, com o valor médio de $0,145 \pm 0,011$. Esta Tabela apresenta, também, o tamanho médio das amostras e o número médio de alelos por locus, que foi $1,7 \pm 0,1$ em todas as estaçōes. Não foram observadas diferenças de alelos fixos entre as estaçōes.
Tabela 1. Resumo de enzimas analisadas

\begin{tabular}{|c|c|c|}
\hline z ima & $\begin{array}{l}\mathrm{N}^{2} \text { de loci } \\
\text { anal isados }\end{array}$ & $\begin{array}{c}\text { Loci } \\
\text { pol imorf icos }\end{array}$ \\
\hline
\end{tabular}

\begin{tabular}{|c|c|c|c|}
\hline Ldh & 2 & Ldh-1(T) & Ldh-2 \\
\hline Mdh & 2 & $M d h-1(M) *, M d h-2(M)$ & \\
\hline Idh & 2 & Idh-1(M)*, Idh-2(M) & \\
\hline Ne & 4 & $\mathrm{Me}-1(M) *, \quad M e-4(M)$ & $\mathrm{Me}-2$, Me-3 \\
\hline Ao & 2 & $A 0-1(M), \quad A 0-2(M)$ & \\
\hline Aat & 1 & Aat-1(D) & \\
\hline Est & 3 & Est-1(M)*, Est-2(M) & Est-3 \\
\hline Aph & 3 & Aph-1(M)*, Aph-2(M) & Aph-3 \\
\hline
\end{tabular}

\section{(M) Monomérico \\ (D) Dimérico \\ (T) Tetramér ico \\ * Loci com alelo nulo}

Foram utilizados 1625 exemplares de krill de ambos os sexos, com comprimento variando de 28 a $50 \mathrm{~mm}$. Não foram observadas, no entanto, diferenças relacionadas ao sexo e ao tamanho do animal.

As freqüências de genótipos observadas em cada locus polimórfico de cada amostra foram comparadas, através de teste de conformidade $\mathrm{X}^{2}$, com as esperadas assumindo o equilíbrio de Hardy-Weinberg. Foram observados apenas quatro loci, entre 252 testes, com desvios significativos do esperado de Hardy-Weinberg. São eles Est-1 $(p=0,004)$ da estação 9; Est-1 $(p=0,030)$ da estação 11; Mdh-1 $(p=0,034)$ e Aph-1 $(p=0,003)$ da estação 18. Todos foram devidos à deficiência de heterozigotos. Os restantes têm valor de p variando entre 0,073 (um locus, Aph-1, estação 8) a 1,0 (um locus, Aat-1, estaçāo 4).

A regiâo de coleta do material para este estudo abrange aproximadamente uma área de $4.600 \mathrm{~km}^{2}$. As coletas foram efetuadas em 18 estaçōes. Para testar a homogeneidade de freqüência de genes, as estaçōes, dependendo de sua posição geográfica, foram agrupadas em sete subáreas que, por sua vez, foram agrupadas em três áreas (Fig. 1). As frequiências de genes em cada locus de cada estaçäo foram comparadas com as da populaçāo de cada área e da área total através da análise de contingência $X^{2}$. Não foram observadas diferenças significativas entre as áreas separadas ou na regiảo de coleta como um todo (Tab. 4). Os resultados dos testes sugerem que não existem diferenças significativas entre os estoques de genes na região de coleta e que os indivíduos coletados em estaçōes 
Tabela 2. Freqüências de alelos em amostras coletadas nas estações de números 1 a 18

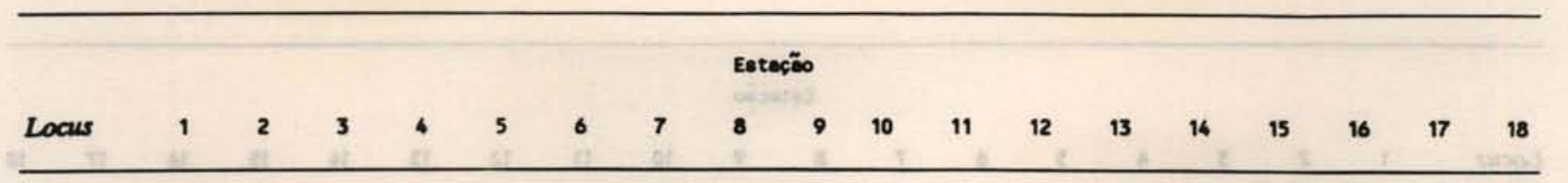

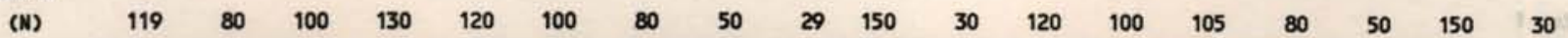

$\begin{array}{lllllllllllllllllllllllll}\text { A } & 0,063 & 0,094 & 0,055 & 0,050 & 0,071 & 0,085 & 0,044 & 0,060 & 0,069 & 0,073 & 0,083 & 0,075 & 0,040 & 0,048 & 0,063 & 0,090 & 0,077 & 0,067\end{array}$

$\begin{array}{llllllllllllllllllllll}\text { B } & 0,937 & 0,906 & 0,945 & 0,950 & 0,929 & 0,915 & 0,956 & 0,940 & 0,931 & 0,927 & 0,917 & 0,925 & 0,960 & 0,952 & 0,938 & 0,910 & 0,923 & 0,933\end{array}$

Ldh-2

$\begin{array}{lrrrrrrrrrrrrrrrrrr}\text { (N) } & 120 & 80 & 100 & 130 & 120 & 100 & 80 & 50 & 30 & 150 & 30 & 120 & 100 & 105 & 80 & 50 & 150 & 30 \\ \text { A } & 1,000 & 1,000 & 1,000 & 1,000 & 1,000 & 1,000 & 1,000 & 1,000 & 1,000 & 1,000 & 1,000 & 1,000 & 1,000 & 1,000 & 1,000 & 1,000 & 1,000 & 1,000\end{array}$

Ndh-1

(N) $\quad \begin{array}{lllllllllllllllllll}120 & 79 & 100 & 130 & 120 & 100 & 80 & 48 & 30 & 150 & 28 & 120 & 100 & 105 & 80 & 50 & 150 & 29\end{array}$

$\begin{array}{lllllllllllllllllllllllll}\text { A } & 0,067 & 0,051 & 0,065 & 0,058 & 0,092 & 0,055 & 0,081 & 0,063 & 0,050 & 0,067 & 0,071 & 0,083 & 0,075 & 0,086 & 0,094 & 0,080 & 0,073 & 0,086\end{array}$

$\begin{array}{llllllllllllllllllll}\text { B } & 0,933 & 0,949 & 0,935 & 0,942 & 0,908 & 0,945 & 0,919 & 0,938 & 0,950 & 0,933 & 0,929 & 0,917 & 0,925 & 0,914 & 0,906 & 0,920 & 0,927 & 0,914\end{array}$

wh-2

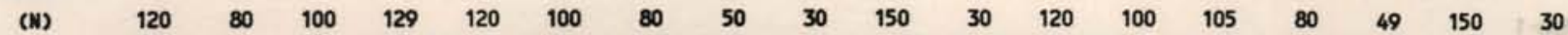

$\begin{array}{lllllllllllllllllllll}\text { A } & 0,071 & 0,056 & 0,085 & 0,058 & 0,054 & 0,075 & 0,094 & 0,060 & 0,100 & 0,097 & 0,067 & 0,079 & 0,090 & 0,057 & 0,069 & 0,061 & 0,063 & 0,050\end{array}$

$\begin{array}{lllllllllllllllllllll}\text { B } & 0,929 & 0,944 & 0,915 & 0,942 & 0,946 & 0,925 & 0,906 & 0,940 & 0,900 & 0,903 & 0,933 & 0,921 & 0,910 & 0,943 & 0,931 & 0,939 & 0,937 & 0,950\end{array}$

Idh-1

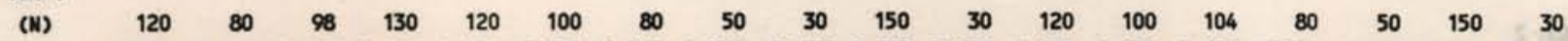

$\begin{array}{lllllllllllllllllllllll}\text { A } & 0,079 & 0,106 & 0,097 & 0,065 & 0,071 & 0,085 & 0,044 & 0,040 & 0,067 & 0,057 & 0,083 & 0,104 & 0,080 & 0,087 & 0,094 & 0,090 & 0,053 & 0,033\end{array}$

$\begin{array}{llllllllllllllllllll}\text { B } & 0,9,921 & 0,894 & 0,903 & 0,935 & 0,929 & 0,915 & 0,956 & 0,960 & 0,933 & 0,943 & 0,917 & 0,896 & 0,920 & 0,913 & 0,906 & 0,910 & 0,947 & 0,967\end{array}$
\end{abstract}

Idh-2

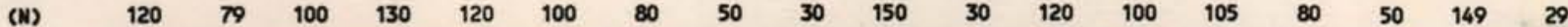
$\begin{array}{llllllllllllllllllll}0,079 & 0,057 & 0,075 & 0,069 & 0,096 & 0,070 & 0,081 & 0,090 & 0,053 & 0,097 & 0,067 & 0,054 & 0,085 & 0,071 & 0,063 & 0,110 & 0,081 & 0,052\end{array}$

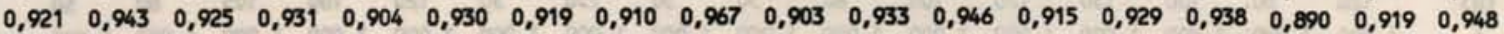

$\begin{array}{llllllllllllllllllllll}\text { (N) } & 120 & 80 & 100 & 130 & 120 & 9 & 79 & 50 & 30 & 150 & 30 & 120 & 100 & 100 & 80 & 50 & 150 & 30\end{array}$

$\begin{array}{llllllllllllllllllllll}\text { A } & 0,108 & 0,112 & 0,075 & 0,085 & 0,104 & 0,091 & 0,120 & 0,070 & 0,133 & 0,093 & 0,067 & 0,079 & 0,090 & 0,110 & 0,119 & 0,080 & 0,123 & 0,150\end{array}$

$\begin{array}{llllllllllllllllllllll}\text { B } & 0,892 & 0,887 & 0,925 & 0,915 & 0,896 & 0,909 & 0,880 & 0,930 & 0,867 & 0,907 & 0,933 & 0,921 & 0,910 & 0,890 & 0,881 & 0,920 & 0,877 & 0,850\end{array}$

Me -2

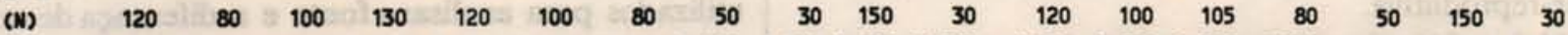

$\begin{array}{llllllllllllllllllllllllll}\text { A } & 1,000 & 1,000 & 1,000 & 1,000 & 1,000 & 1,000 & 1,000 & 1,000 & 1,000 & 1,000 & 1,000 & 1,000 & 1,000 & 1,000 & 1,000 & 1,000 & 1,000 & 1,000\end{array}$

Me -3

(N) $\quad \begin{array}{lllllllllllllllllll} & 120 & 80 & 100 & 130 & 120 & 100 & 80 & 50 & 30 & 150 & 30 & 120 & 100 & 105 & 80 & 50 & 150 & 30\end{array}$

$\begin{array}{lllllllllllllllllllllllll}\text { A } & 1,000 & 1,000 & 1,000 & 1,000 & 1,000 & 1,000 & 1,000 & 1,000 & 1,000 & 1,000 & 1,000 & 1,000 & 1,000 & 1,000 & 1,000 & 1,000 & 1,000 & 1,000\end{array}$

Ne -4

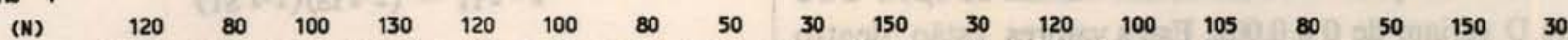

$\begin{array}{llllllllllllllllllll}\text { A } & 0,938 & 0,962 & 0,945 & 0,923 & 0,933 & 0,955 & 0,950 & 0,970 & 0,917 & 0,920 & 0,917 & 0,946 & 0,930 & 0,914 & 0,906 & 0,900 & 0,957 & 0,883\end{array}$

$\begin{array}{llllllllllllllllllllllll}\text { B } & 0,063 & 0,038 & 0,055 & 0,077 & 0,067 & 0,045 & 0,050 & 0,030 & 0,083 & 0,080 & 0,083 & 0,054 & 0,070 & 0,086 & 0,094 & 0,100 & 0,043 & 0,117\end{array}$

Ao -1

(W) $\quad \begin{array}{lllllllllllllllllll}120 & 80 & 100 & 130 & 120 & 100 & 79 & 50 & 30 & 150 & 30 & 120 & 100 & 105 & 79 & 50 & 149 & 30\end{array}$ $\begin{array}{llllllllllllllllllllllllll}0,154 & 0,206 & 0,135 & 0,146 & 0,167 & 0,190 & 0,184 & 0,180 & 0,150 & 0,173 & 0,233 & 0,179 & 0,165 & 0,195 & 0,177 & 0,130 & 0,148 & 0,200\end{array}$ $\begin{array}{llllllllllllllllllll}0,846 & 0,794 & 0,865 & 0,854 & 0,833 & 0,810 & 0,816 & 0,820 & 0,850 & 0,827 & 0,767 & 0,821 & 0,835 & 0,805 & 0,823 & 0,870 & 0,852 & 0,800\end{array}$

Ao -2

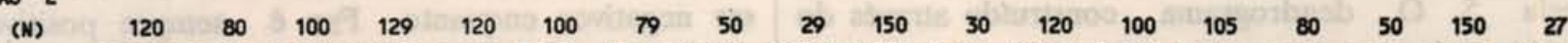
$\begin{array}{lllllllllllllllllll}0,067 & 0,094 & 0,055 & 0,058 & 0,083 & 0,060 & 0,063 & 0,080 & 0,052 & 0,087 & 0,033 & 0,075 & 0,090 & 0,076 & 0,106 & 0,050 & 0,077 & 0,037\end{array}$ $\begin{array}{llllllllllllllllllll}0,933 & 0,906 & 0,945 & 0,942 & 0,917 & 0,940 & 0,937 & 0,920 & 0,948 & 0,913 & 0,967 & 0,925 & 0,910 & 0,924 & 0,894 & 0,950 & 0,923 & 0,963\end{array}$

Aat-1

$\begin{array}{lllllllllllllllllllll}\text { (N) } & 120 & 80 & 100 & 130 & 120 & 100 & 80 & 50 & 30 & 150 & 30 & 120 & 100 & 105 & 80 & 48 & 150 & 30\end{array}$ $\begin{array}{llllllllllllllllllll}0,450 & 0,381 & 0,360 & 0,431 & 0,392 & 0,440 & 0,381 & 0,460 & 0,350 & 0,447 & 0,467 & 0,400 & 0,455 & 0,433 & 0,369 & 0,365 & 0,410 & 0,383\end{array}$ $\begin{array}{llllllllllllllllllllll}0,550 & 0,619 & 0,640 & 0,569 & 0,608 & 0,560 & 0,619 & 0,540 & 0,650 & 0,553 & 0,533 & 0,600 & 0,545 & 0,567 & 0,631 & 0,635 & 0,590 & 0,617\end{array}$

$\mathrm{N}=$ Número de exemplares. 
Tabela 2. Continuação

Estaç̄o

$\begin{array}{lllllllllllllllllll}\text { Locus } & 1 & 2 & 3 & 4 & 5 & 6 & 7 & 8 & 9 & 10 & 11 & 12 & 13 & 16 & 15 & 16 & 17 & 18\end{array}$

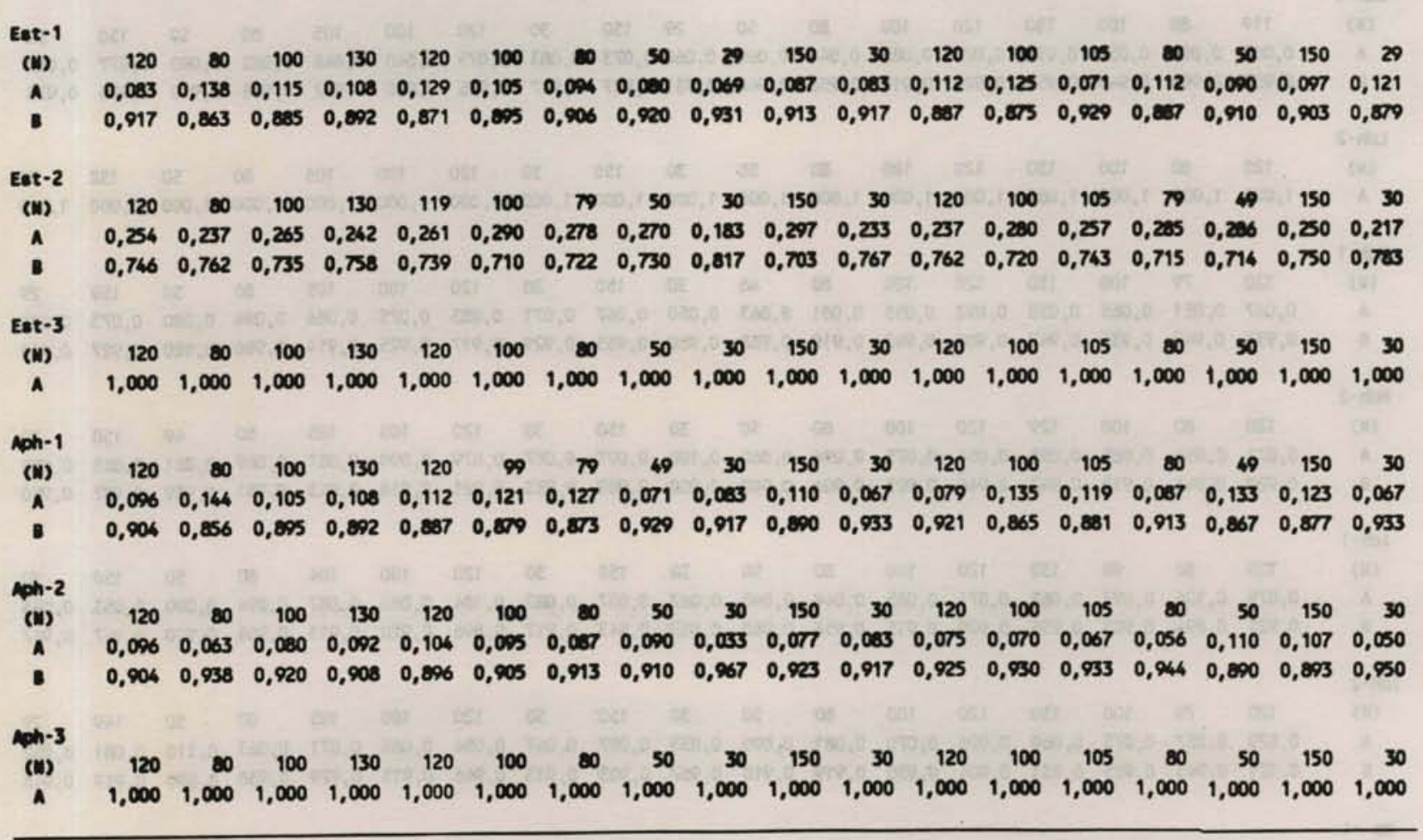

diferentes pertencem a uma só população inter-reprodutiva.

Mais evidências da homogeneidade genética do krill na regiāo estudada são encontradas nas estimativas de índices de similaridade genética $I$ e de distância genética D (Nei, 1972) entre as amostras coletadas nas diferentes estaçōes. Os valores de I variam de 0,998 a 1 e os de $\mathrm{D}$ variam de 0 a 0,002 . Estes valores estão dentro dos limites freqüentemente encontrados entre amostras coletadas em diferentes locais de ocorrência de uma mesma espécie (Avise, 1974; Ferguson, 1980) e nos krill considerados como da mesma população com acasalamento ao acaso (Fevolden, 1986). Os valores de D estão na matriz de distância genética apresentada na Tabela 5. O dendrograma construído através do método de agrupamento de pares por média aritmética não ponderada, UPGMA (Sneath \& Sokal, 1973) utilizando estes valores encontra-se na Figura 2. No dendrograma, os ramos com os índices de distância genética maior do que 0,0015 são constituídos de amostras (estaçōes) de pequeno número de exemplares.
Os F-estatísticos (Wright, 1965, 1978; Nei, 1977) foram utilizados para analisar a fonte $\mathrm{e}$ a diferença de variação genética, dentro de uma amostra individual e entre as amostras coletadas em diferentes estaçōes. A fórmula básica utilizada é:

$$
1-\mathrm{F}_{\mathrm{IT}}=\left(1-\mathrm{FIS}_{\mathrm{IS}}\right)\left(1-\mathrm{FST}_{\mathrm{ST}}\right.
$$

onde FIS e FrT são, respectivamente, os índices de fixaçäo relativos às amostras individuais e à amostra total. FIS e Frr representam os desvios médios do equilíbrio de Hardy-Weinberg nas amostras individuais e na amostra total. FST representa a quantia de variação de freqüência do alelo entre as amostras individuais. FIS e FIT podem ser negativos enquanto FST é sempre positivo. A significância do FST foi avaliada utilizando $\mathrm{X}^{2}$ calculado de acordo com Workman \& Niswander (1970): $\mathrm{X}^{2}=$ 2NTFST $(k-1)$ onde $N_{T}=$ número total de indivíduos examinados, $\mathbf{k}=$ número de alelos e $\mathbf{s}=$ número de amostras com (k-1)(s-1) graus de liberdade. A significância de FIS foi testada de acordo com Li (1955): $\mathrm{X}^{2}=\mathrm{NF}_{\mathrm{IS}}{ }^{2}$. A significância de FrT foi testada de acordo 
Tabela 3. Variabilidade genética em todos os loci de todas as amostras

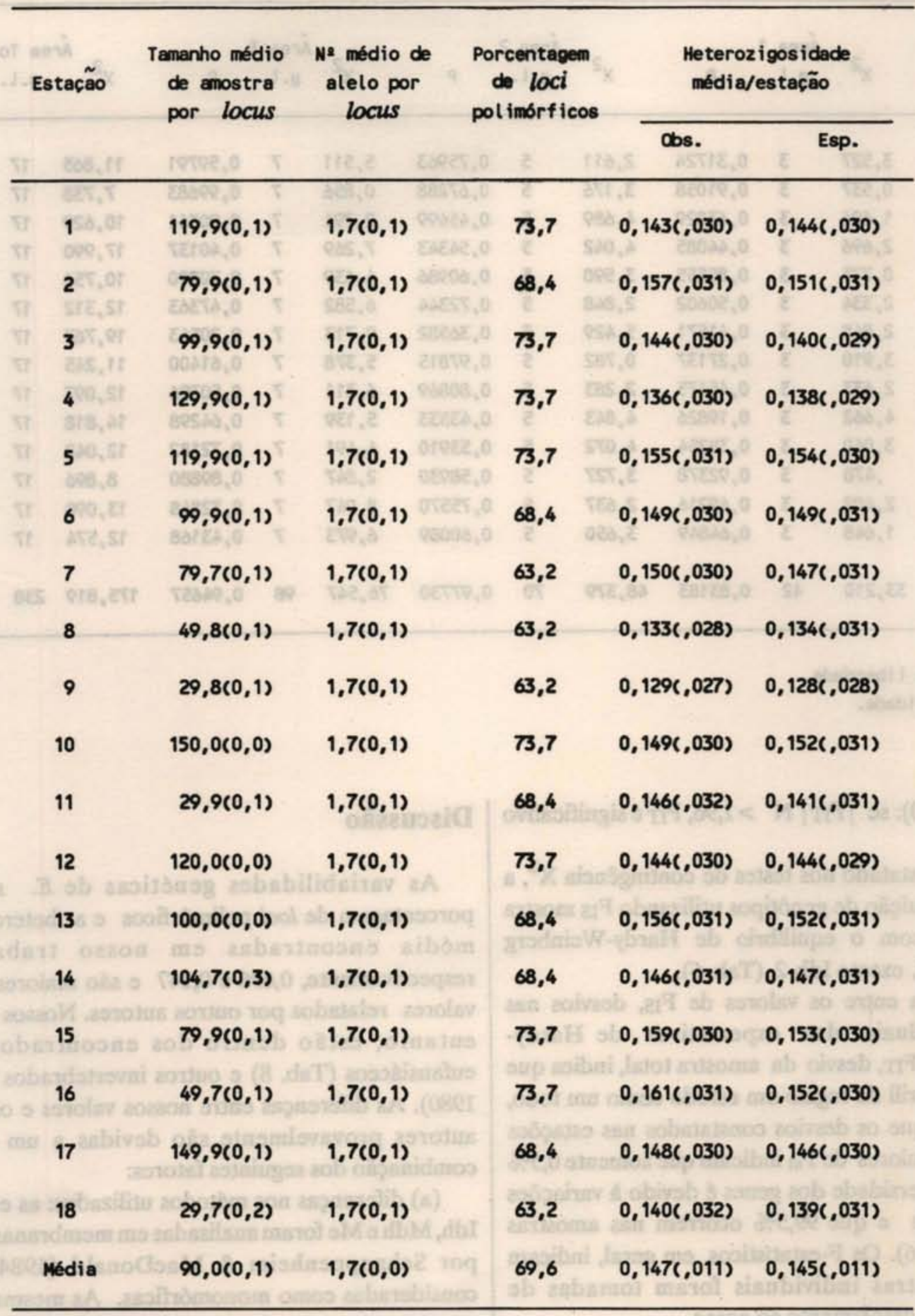

Un locus é considerado polimórfico se a frequência do alelo mais comum não for maior que 0,95 .

(erro padrão entre parênteses).

Obs. $=$ observado

Esp. $=$ esperado 
Tabela 4. Teste de contigência $x^{2}$ para todos os loci de todas áreas

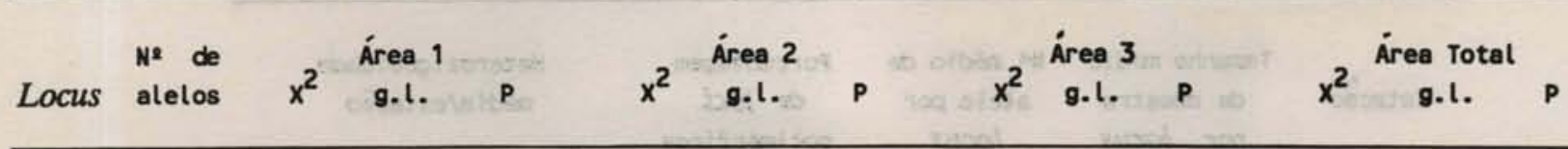

\begin{tabular}{llllllllllllll}
\hline Ldh1 & 2 & 3,527 & 3 & 0,31724 & 2,611 & 5 & 0,75963 & 5,511 & 7 & 0,59791 & 11,865 & 17 & 0,80824 \\
Mdh1 & 2 & 0,537 & 3 & 0,91058 & 3,176 & 5 & 0,67288 & 0,856 & 7 & 0,99683 & 7,738 & 17 & 0,97183 \\
Mdh2 & 2 & 1,694 & 3 & 0,63829 & 4,689 & 5 & 0,45499 & 2,791 & 7 & 0,90361 & 10,629 & 17 & 0,87518 \\
Idh1 & 2 & 2,696 & 3 & 0,44085 & 4,042 & 5 & 0,54343 & 7,269 & 7 & 0,40137 & 17,990 & 17 & 0,38949 \\
Idh2 & 2 & 0,775 & 3 & 0,85555 & 3,590 & 5 & 0,60986 & 4,639 & 7 & 0,70390 & 10,756 & 17 & 0,86896 \\
Me 1 & 2 & 2,334 & 3 & 0,50602 & 2,848 & 5 & 0,72344 & 6,582 & 7 & 0,47363 & 12,312 & 17 & 0,78091 \\
Me 4 & 2 & 2,848 & 3 & 0,41571 & 5,429 & 5 & 0,36582 & 9,713 & 7 & 0,20543 & 19,767 & 17 & 0,28632 \\
Ao 1 & 2 & 3,910 & 3 & 0,27137 & 0,782 & 5 & 0,97815 & 5,378 & 7 & 0,61400 & 11,245 & 17 & 0,84354 \\
Ao 2 & 2 & 2,633 & 3 & 0,45175 & 2,283 & 5 & 0,80869 & 6,311 & 7 & 0,50396 & 12,097 & 17 & 0,79421 \\
Aat1 & 2 & 4,662 & 3 & 0,19826 & 4,843 & 5 & 0,43533 & 5,139 & 7 & 0,64298 & 14,818 & 17 & 0,60862 \\
Est1 & 2 & 3,060 & 3 & 0,38254 & 4,072 & 5 & 0,53910 & 4,491 & 7 & 0,72182 & 12,042 & 17 & 0,79758 \\
Est2 & 2 &, 478 & 3 & 0,92378 & 3,727 & 5 & 0,58930 & 2,847 & 7 & 0,89880 & 8,896 & 17 & 0,94347 \\
Aph1 & 2 & 2,408 & 3 & 0,49216 & 2,637 & 5 & 0,75570 & 8,047 & 7 & 0,32848 & 13,090 & 17 & 0,73011 \\
Aph2 & 2 & 1,648 & 3 & 0,64849 & 3,650 & 5 & 0,60089 & 6,973 & 7 & 0,43168 & 12,574 & 17 & 0,76420 \\
& & & & & & & & & & & & & \\
Total & & 33,210 & 42 & 0,83183 & 48,379 & 70 & 0,97730 & 76,547 & 98 & 0,94657 & 175,819 & 238 & 0,99908 \\
& & & & & & & & & & & & & \\
\hline
\end{tabular}

g.l. = graus de $\mathrm{t}$ iberdade.

$P=$ probabil idade.

com Brown (1970): se $|\mathrm{FrT}| \mathrm{N}>1,96$, Frr é significativo ao nível $5 \%$.

Como foi constatado nos testes de contingência $\mathbf{X}^{2}$, a análise da distribuição de genótipos utilizando Fis mostra a conformidade com o equilibrio de Hardy-Weinberg para todos os loci, exceto Idh-2 (Tab. 6).

A semelhança entre os valores de Fis, desvios nas amostras individuais das expectativas de HardyWeinberg e de FrT, desvio da amostra total, indica que o desvio para o krill da regiâo em estudo como um todo, nāo é maior do que os desvios constatados nas estaçōes individuais. Os valores de $\mathrm{F}_{\text {st }}$ indicam que somente $0,5 \%$ do total da diversidade dos genes $e$ devido à variaçōes entre as amostras e que $99,5 \%$ ocorrem nas amostras individuais (Tab. 6). Os F-estatísticos, em geral, indicam que as amostras individuais foram tomadas de populaçōes com acasalamento ao acaso.

Os F-estatísticos podem ser utilizados para a análise hierárquica da diferenciação populacional. Utilizando-se as divisōes da regiâo de amostragem em áreas, subáreas e estaçōes (Fig. 1) como níveis hierárquicos, os Festatísticos, para cada um dos níveis da hierarquia em relação a outros níveis, mostram que as variaçōes entre as áreas não são maiores do que as variaçōes entre as subáreas, ou as variaçōes entre as amostras (Tab. 7).

\section{Discussão}

As variabilidades genéticas de $E$. superba, a porcentagem de loci polimórficos e a heterozigosidade média encontradas em nosso trabalho são, respectivamente, 0,696 e 0,147 e são maiores do que os valores relatados por outros autores. Nossos valores, no entanto, estão dentro dos encontrados para os eufausiáceos (Tab. 8) e outros invertebrados (Ferguson, 1980). As diferenças entre nossos valores e os de outros autores provavelmente são devidas a um ou a uma combinação dos seguintes fatores:

(a) diferenças nos métodos utilizados: as enzimas Ao, Idh, Mdh e Me foram analisadas em membranas de acetato por Schneppenheim \& MacDonald (1984) e foram consideradas como monomórficas. As mesmas enzimas, no entanto, quando por nós analisadas em gel de poliacrilamida foram constatadas como polimórficas.

(b) loci polimorficos com alelo nulo: nenhum locus com alelo nulo foi analisado por outros autores. $\mathrm{O}$ alelo nulo é um alelo que ou não produz uma proteína ou produz uma proteína enzimaticamente não funcional. Os homozigotos de um alelo nulo não aparecem como uma banda no eletroferograma se a revelação depende da atividade enzimática e os heterozigotos aparecem como 
uma banda de intensidade reduzida. $\mathrm{O}$ alelo nulo, no caso normal, provavelmente só pode ser encontrado em organismos poliploides ou em organismos com loci duplicados (Ferguson, 1980). Especulaçōes sobre a sua existência, no entanto, sāo apresentadas em muitos trabalhos como uma possível causa do excesso de homozigotos em invertebrados (Fujio et al., 1983) e vertebrados (Smith et al., 1981). Nos estudos eletroforéticos anteriores sobre o krill, o alelo nulo foi encontrado em um só homozigoto de um único locus

Tabela. 5. Matriz de distância genética (Nel, 1972)

$\begin{array}{llllllllllllllllllllll}\text { Estaça } & 1 & 2 & 3 & 4 & 5 & 6 & 7 & 8 & 9 & 10 & 11 & 12 & 13 & 14 & 15 & 16 & 17 & 18\end{array}$
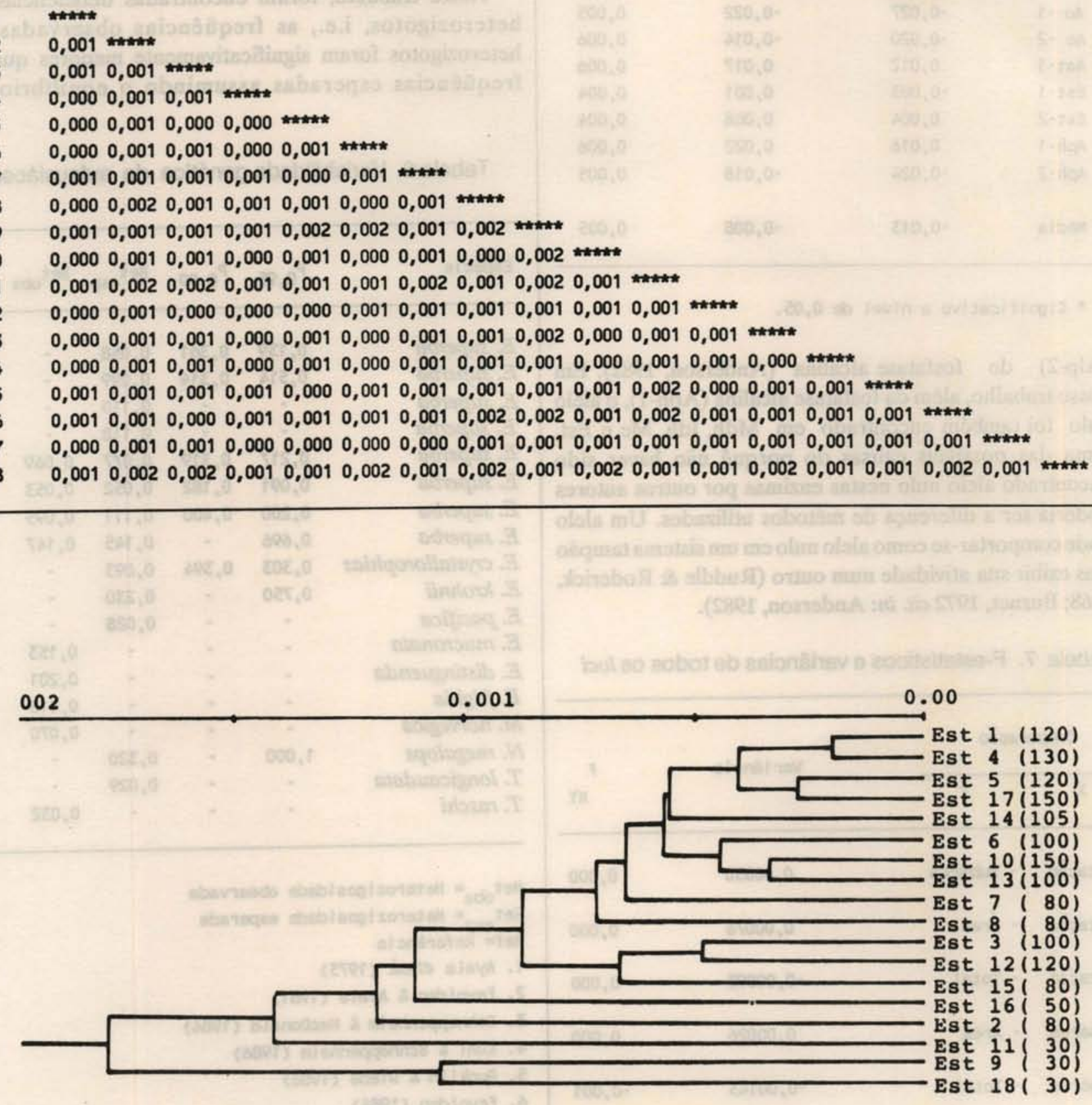

Fig. 2. Dendograma UPGMA (Sneath \& Sokal, 1973) de distância genética (Nei, 1972) de krill coletados em 18 estações (Est) diferentes na região de estudo. $O$ número de exemplares examinados em cada estação está entre parênteses. 
Tabela 6. Sumário de F-estatísticos para todos os loci

\begin{tabular}{lccc}
\hline Locus & F(IS) & $F(I T)$ & $F(S T)$ \\
\hline & & & \\
Ldh-1 & $-0,022$ & $-0,018$ & 0,004 \\
Mdh-1 & 0,004 & 0,007 & 0,003 \\
Mdh-2 & $-0,028$ & $-0,025$ & 0,004 \\
Idh-1 & $-0,047$ & $-0,040$ & 0,007 \\
Idh-2 & $-0,061^{*}$ & $-0,056^{*}$ & 0,005 \\
Me -1 & $-0,038$ & $-0,032$ & 0,006 \\
Me -4 & $-0,039$ & $-0,031$ & 0,008 \\
Ao -1 & $-0,027$ & $-0,022$ & 0,005 \\
Ao -2 & $-0,020$ & $-0,014$ & 0,006 \\
Aat-1 & 0,012 & 0,017 & 0,006 \\
Est-1 & $-0,003$ & 0,001 & 0,004 \\
Est-2 & 0,004 & 0,008 & 0,004 \\
Aph-1 & 0,016 & 0,022 & 0,006 \\
Aph-2 & $-0,024$ & $-0,018$ & 0,005 \\
& & & \\
Média & $-0,013$ & $-0,008$ & 0,005 \\
& & & \\
\hline
\end{tabular}

* Significativo a nível de 0,05 .

(Alp-2) de fosfatase alcalina (Anderson, 1982). Em nosso trabalho, além da fosfatase alcalina (Aph-1), o alelo nulo foi também encontrado em Mdh, Idh, Me e Est. Uma das possíveis causas do porquê não haver sido encontrado alelo nulo nestas enzimas por outros autores poderia ser a diferença de métodos utilizados. Um alelo pode comportar-se como alelo nulo em um sistema tampão mas exibir sua atividade num outro (Ruddle \& Roderick, 1968; Burnet, 1972 cit. in: Anderson, 1982).

Tabela 7. F-estatísticos e variâncias de todos os loci

\begin{tabular}{|c|c|c|c|}
\hline \multicolumn{2}{|c|}{ Comparação } & \multirow{2}{*}{ Variância } & \multirow{2}{*}{${ }_{X Y}^{F}$} \\
\hline$x$ & $\mathbf{Y}$ & & \\
\hline Estaçao & - subárea & 0,00050 & 0,000 \\
\hline Estação & - Área & 0,00076 & 0,000 \\
\hline Estação & - Total & $-0,00093$ & $-0,000$ \\
\hline subárea & - Área & 0,00026 & 0,000 \\
\hline subárea & - Total & $-0,00143$ & $-0,001$ \\
\hline Área & - Total & $-0,00169$ & $-0,001$ \\
\hline
\end{tabular}

(c) Diferenças de loci e enzimas estudadas: não foram estudadas em nosso trabalho as enzimas de pequena variabilidade genética e não se sabe se os mesmos loci de uma mesma enzima constam tanto em nosso trabalho quanto em trabalhos realizados por outros autores.

(d) Conservação das amostras: em nosso trabalho, imediatamente após a captura, as amostras de krill foram conservadas a $-20^{\circ} \mathrm{C}$; enquanto que foram conservadas a $-80^{\circ} \mathrm{C}$ por outros autores. Em nosso trabalho não foram detectadas, entretanto, diferenças entre zimogramas obtidos de amostras de krill conservados e de krill sacrificados no dia da análise eletroforética.

Neste trabalho, foram encontradas deficiências de heterozigotos, i.e., as freqüências observadas de heterozigotos foram significativamente menores que as freqüências esperadas assumindo o equilíbrio de

Tabela 8. Variabilidade genética de eufausiáceos

Especie $\quad P_{0,95} P_{0,99}$ Het $_{\text {esp }}$ Het ${ }_{\text {obs Ref }}$

\begin{tabular}{lccccc}
\hline E. superba & 0,139 & 0,361 & 0,058 & - & 1 \\
E. superba & 0,514 & 0,314 & 0,099 & - & 2 \\
E. superba & - & - & 0,110 & - & 3 \\
E. superba & - & - & 0,118 & - & 4 \\
E. superba & 0,217 & 0,319 & 0,077 & 0,069 & 7 \\
E. superba & 0,091 & 0,182 & 0,052 & 0,053 & 7 \\
E. superba & 0,200 & 0,400 & 0,111 & 0,095 & 7 \\
E. superba & 0,696 & - & 0,145 & 0,147 & pt \\
E. crystallorophias & 0,303 & 0,394 & 0,093 & - & 2 \\
$E$. krohnii & 0,750 & - & 0,230 & - & 5 \\
$E$. pacifica & - & - & 0,028 & - & 6 \\
E. mucronata & - & - & - & 0,153 & 6 \\
E. distinguenda & - & - & - & 0,201 & 6 \\
E. frigida & - & - & - & 0,110 & 6 \\
$M$. norvegica & - & - & - & 0,070 & 6 \\
$N$. megalops & 1,000 & - & 0,320 & - & 5 \\
$T$. longicaudata & - & - & 0,029 & - & 7 \\
$T$. raschi & - & - & - & 0,032 & 6 \\
& & & & & \\
\hline & & & & &
\end{tabular}

Het obs $=$ Heterozigosidade observada

Het esp $^{=}$Heteroz igos idade esperada

Ref $=$ Referência

1. Ayala et al. (1975)

2. Fevolden \& Ayala (1981)

3. Schneppenheim \& MacDonald (1984)

4. KÖhl \& Schneppenheim (1986)

5. Buckl in \& Wiebe (1986)

6. Fevolden (1984)

7. Anderson (1982)

pt: presente trabalho 
Hardy-Weinberg, nos loci Aph-1 das estaçōes 8 e 18, Est-1 das estaçōes 9 e 11 e Mdh-1 da estação 18 . Nos invertebrados, a deficiência de heterozigotos pode ser explicada por vários fatores (Fujio et al., 1983), entre os quais, os mais comuns, são erros na interpretação dos fenótipos, efeito de Wahlund, alelo nulo, endocruzamentos, etc. $\mathbf{O}$ efeito de Wahlund, i.e., a amostragem de uma mistura de duas ou mais populaçōes distintas, é pouco provável, pois nāo foram encontradas neste trabalho distribuiçōes heterogêneas de alelos. Levando em consideração o fato de que todos são loci com alelo nulo e provenientes de amostras com tamanhos relativamente pequenos, é muito provável que a deficiência encontrada seja devida à dificuldade na contagem dos fenótipos. A análise de alelo nulo foi considerada como particularmente difícil (Utter et al., 1986). Num locus com alelo nulo, a diferença entre heterozigotos e homozigotos de um alelo está apenas na intensidade da banda. Um heterozigoto, neste caso, pode ser confundido com um homozigoto, o que resultará na deficiência de heterozigotos e excesso de homozigotos na comparação com os esperados de Hardy-Weinberg.

Nossos resultados indicam que não existem evidências de diferenciação genética entre as amostras coletadas em 18 localidades diferentes do Estreito de Bransfield, da Passagem Drake e do oeste da Península Antártica. Nossos resultados apoiam a hipótese de que todas as amostras foram tomadas de uma única população com acasalamento ao acaso e concordam com os de Schneppenheim \& MacDonald (1984), Fevolden (1986), e Kühl \& Schneppenheim (1986). Os resultados de estudos bioquímicos sobre a homogeneidade genética do krill no Estreito são apoiados por estudos morfologicos. Siegel (1983) não conseguiu discriminar diferenças entre os krill do Mar de Bellingshausen, do Estreito de Bransfield e do norte e sudeste do Mar de Weddell. utilizando características morfologicas. Fevolden \& George (1984) não conseguiram discriminar os estoques de krill a oeste da Península, utilizando somente informaçōes sobre distribuição de comprimento. Nossos resultados, no entanto, não estão de acordo com os dados obtidos por Fevolden \& Ayala (1981) e por Anderson (1982), a respeito da existência de populações separadas de krill no oeste e leste da Península Antártica.

A homogeneidade genética do krill parece ter uma extensão ainda maior. Fevolden \& Schneppenheim (1989), estudaram as variaçōes de alozimas em animais coletados no Mar de Ross e no Mar de Bellingshausen no Setor Pacífico do Oceano Antártico e compararam com os resultados obtidos em vários locais no Setor Atlântico (Schrieppenheim \& MacDonald, 1984; Kühl \& Schneppenheim, 1986) e na Baía Prydz no Setor f́ndico (MacDonald et al., 1986). Esses autores concluiram que nẩo existe nenhuma evidência de estrutura populacional do krill do Setor Pacífico e que o krill deste Setor, não pode ser diferenciado geneticamente do krill do Setor Atlântico ou f́ndico através de método eletroforético. Apesar da pequena quantidade de loci analisados, os resultados obtidos levaram os autores a sugerir a hipótese de uma única população circumpolar de krill, com acasalamento ao acaso. Esta hipótese, de acordo com MacDonald \& Schneppenheim (1983), não exige o movimento de um número substancial de krill, em toda extensāo da distribuição da espécie durante uma única geração. Os autores acreditam que, mesmo que existam áreas de desova geograficamente isoladas, o intercruzamento de krill nas áreas adjacentes seria suficiente para que todos os estoques possam ser considerados como parte de uma única população inter-reprodutiva.

A homogeneidade genética do krill, encontrada através do polimorfismo de proteínas no Estreito de Bransfield, é provavelmente uma conseqüência da sua capacidade de dispersarem-se em longas distâncias, de misturarem-se entre si e de tolerarem as condiçōes ambientais. A dispersāo impede o isolamento local, a mistura facilita o intercâmbio gênico, e a tolerância promove a sobrevivência e o sucesso na reproduçāo. Vários fatores, físicos e biológicos, isolados e/ou em conjunto, governam esses processos.

O Estreito de Bransfield, área principal da coleta de material para este trabalho, $\in$ essencialmente uma faixa de água de $100 \mathrm{~km}$ de largura, estendendo-se de sudoeste a nordeste entre as Illhas Shetland do Sul e a Península Antártica, e da Ilha Low à Illha Clarence numa extensão de cerca de $460 \mathrm{~km}$ (Fig. 1). Do lado sudoeste uma corrente, de água do Mar de Bellingshausen, entra no Estreito e flui ao longo da costa sul das Ilhas Shetland do Sul. Do lado sudeste uma corrente de água do Mar de Weddell espalha-se ao longo da costa da Península Antártica, às vezes até a llha Trinity, onde se une com a corrente de água proveniente do Mar de Bellingshausen. O krill do Estreito de Bransfield e do norte das Ilhas Shetland do Sul, de acordo com Wolnomiejski $e$ t al. (1982), tem origem no Mar de Weddell e no Mar de Bellingshausen. Uma vez entrando no Estreito, as duas correntes superficiais, de direçōes opostas, juntamente com a água relativamente estável no fundo do Estreito, podem fazer com que o krill de origens diferentes se torne uma mistura giratória dentro do mesmo.

No ambiente marinho, o fluxo de genes entre as populaçōes de invertebrados provavelmente ocorre, mais freqüentemente, pela dispersão de larvas planctônicas (Burton, 1983). Os animais com larvas pelágicas, comparados aos animais de larvas bentônicas, são geralmente considerados como pouco variáveis geneticamente, devido à sua maior capacidade de dispersāo (Scheltema, 1971). Os ovos de krill depois da 
fertilizaçāo caem na plataforma continental na regiāo costeira ou até $3000 \mathrm{~m}$ de profundidade na regiāo oceânica, eclodem como náuplios e sobem para a surperfície como calyptopis. A viagem de descida e subida dura em torno de 21 a 30 dias, dependendo do autor. Durante estes dias os processos verticais os levam às circulações oceânicas, onde permanecem àmercê de correntes durante cerca de 100 dias, antes de completarem as fases de desenvolvimento como larvas. Apesar de serem considerados como organismos planctônicos, os adultos, por outro lado, são muito ativos e são excelentes nadadores. Marr (1962) observou um cardume de krill nadar contra a corrente com velocidade de $18 \mathrm{~cm} \cdot \mathrm{s}^{-1}$. Kanda et al. (1982) observaram cardumes migrando contra a corrente de água com velocidade média de $11,6-12,9 \mathrm{~cm} \cdot \mathrm{s}^{-1}$ numa distância de $186,5 \mathrm{~km}$. A deriva passiva de ovos e larvas e a migraçāo ativa de jovens e adultos podem funcionar como mecanismos de dispersảo que impedem o processo de adaptação às condições locais.

A água na área do Estreito de Bransfield é uma conseqüência da complexa interação entre as águas do Mar de Bellingshausen, do Mar de Weddell e das características locais. Em geral, a água mais quente e menos salgada com origem no Mar de Bellingshausen, é dominante a sudoeste do Estreito e ao sul das Ilhas Shetland do Sul; a água mais fria e mais salgada, originária do Mar de Weddell, é dominante a sudeste do Estreito e ao norte da Península. Oito massas de água foram identificadas no Estreito e na sua proximidade, como resultado da mistura destes dois tipos de água (BIOMASS, 1982, 1983). Variaçōes a curto prazo e variaçōes interanuais na distribuiçāo destas massas de água têm uma correlaçāo marcante com o acúmulo do krill (Makarov et al., 1987). Em alguns locais, no entanto, as flutuaçōes hidro-meteorológicas a longo prazo, podem alterar as condiçōes hidrodinâmicas e, conseqüentemente, a distribuição do krill (Maslennikov \& Solyankin, 1987). Fatores ambientais como salinidade, temperatura, nutrientes e concentração de oxigênio, no entanto, parecem nāo governar diretamente a distribuiçāo do krill (Kalinowski \& Witek, 1985; Godlewska \& Rakusa-Suszczewski 1988; Katsuragawa et al., 1989). As variaçōes destes fatores no Estreito estāo, na verdade, dentro dos limites de tolerância dos cardumes de krill determinados por Rakusa-Suszczewski (1978). Desse modo, é provável que no Estreito de Bransfield, bem como na área total de ocorrência do krill, i.e., entre o Continente Antártico e a Convergência Antártica, não existam condiçōes hidrodinâmicas e físico-químicas suficientemente persistentes para atuarem como barreira ambiental para a formaçāo de populaçōes geneticamente isoladas.
No Oceano Antártico apenas o krill das áreas a oeste da Península, Estreito de Bransfield, Mar de Scotia e Mar de Weddell foi estudado repetidamente, com certo grau de detalhamento em termos de número de loci e número de locais de amostragem. Em outras áreas somente alguns loci de algumas amostras foram examinados. Para uma melhor compreensāo da populaçāo circumpolar do krill é necessário que um número maior de loci de animais, coletados em maior numero de locais em todos os setores do Oceano Antártico, seja examinado. E necessário também a aplicaçāo de outros métodos genéticos para esta investigação. A análise eletroforética só pode revelar uma fração de variantes genéticos (Hubby \& Lewontin, 1966). Além de mutaçōes redundantes, muitas substituiçōes de aminoácidos não resultam em carga ou variação configuracional suficientes para poderem ser detectadas por esta técnica.

Além dos dados eletroforéticos existem alguns trabalhos isolados sobre a citogenética de krill. Yabu \& Kawamura (1984), obtiveram de 15 machos, coletados em duas localidades à leste da Antártica, metáfases com n = 16 e $2 \mathrm{n}=32$. Phan et al. (1989) obtiveram de quatro machos coletados à oeste do Continente 47 metáfases de boa qualidade, todas com $\mathbf{n}=17$ bivalentes.

E provável que a diferença de um cromossomo meiótico acima citada seja devida à diferença de métodos utilizados. Para obtenção dos cromossomos Phan et al. (1989) utilizaram suspensāo de células hipotonizadas de glândula seminal de krill injetado com colchicina, enquanto que os autores japoneses utilizaram a dissecção daquela glândula de krill, fixada em álcool:ácido acético (3:1) imediatamente após a captura. É também possível que a diferença no número de cromossomos reflita diferença genética existente entre krill coletados em diferentes localidades. Os exemplares utilizados no estudo de Phan et al. (1989), foram coletados num lugar afastado dentro da Baía do Almirantado, enquanto que os animais utilizados no trabalho de Yabu \& Kawamura (1984), foram coletados no mar aberto do lado oposto do Continente. Para explicar as possíveis causas e implicaçōes desta diferença é necessário um estudo mais detalhado.

Além de estudos genéticos, conhecimentos relacionados aos impactos diferenciais do ambiente sobre as características da espécie são também necessários. São conhecimentos indispensáveis para a compreensão e a integração dos dados obtidos através de diversas investigaçōes.

\section{Conclusões}

Baseando-se nos dados obtidos através dos estudos eletroforéticos de krill coletado na região da Passagem Drake-Estreito de Bransfield-oeste da Península Antártica conclui-se que: 
Não foram encontradas diferenças em freqüências de alelos dos loci examinados em função do sexo e do tamanho dos animais.

O krill coletado em diferentes localidades pertence à uma única população geneticamente homogênea. Sistemas de circulação, densidade da população, capacidade de dispersão e tolerância às condiçōes ambientais, como também as interaçōes entre os mesmos, são considerados como os fatores que promovem esta homogeneidade.

E necessário um estudo mais detalhado, utilizando várias técnicas distintas, para analisar uma grande quantidade de amostras coletadas no maior número possível de localidades ao redor do Continente, para compreender melhor a estrutura populacional circumpolar do krill no Oceano Antártico.

\section{Agradecimentos}

Agradecemos ao Programa Antártico Brasileiro, PROANTAR/CNPq, à Comissão Interministerial para os Recursos do Mar, CIRM, e ao Instituto Oceanográfico da Universidade de São Paulo, pela oportunidade, apoio logístico e financeiro para realizar este trabalho. Ao Conselho Nacional de Desenvolvimento Científico e Tecnológico pela bolsa de pesquisa concedida (Proc. $300299 / 77-0)$. À tripulaçāo e equipes científicas das Expediçōes Antárticas do N/Oc. "Prof. W. Besnard" pelo material coletado. À Estação Antártica Brasileira "Comandante Ferraz" pela hospitalidade e apoio durante os trabalhos de campo. À Srta. Lucy Teixeira pela padronizaçāo das referências bibliográficas e à Marizilda Magro pelas ilustrações.

\section{Referências bibliográficas}

AKROYD, P. 1967. Acrylamide gel slab electrophoresis in a simple glass cell for improved resolution and comparison of serum proteins. Analyt. Biochem., 19:399-410.

ANDERSON, R. C. 1982. Isozyme variation in euphausiids. PhD. Thesis. University of East Anglia, Fisheries Laboratory. Lowestoft. 184p.

AVISE, J. C. 1974. Systematic value of electrophoretic data. Syst. Zool., 23:465-481.

AYALA, F. J.; VALENTINE, J. W. \& ZUMWALT, G. S. 1975. An electrophoretic study of the Antarctic zooplankter Euphausia superba. Limnol. Oceanogr., 20:635-640.
BIOMASS. 1982. 1st Post-FIBEX Hydrographic Data Interpretation Workshop, Hamburg FRG, 20-26 September 1982. BIOMASS Rep. Ser., 30. 11 .

1983. 2nd Post-FIBEX Hydrographic Data Interpretation Workshop, Hamburg FRG, 16-20 May 1983. BIOMASS Rep. Ser., 31. 26p.

BROWN, A. H. D. 1970. The estimation of Wright's fixation index from genotypic frequencies. Genetica, 41:399-406.

BUCKLIN, A. \& WIEBE, P. H. 1986. Genetic heterogeneity in euphausiid populations: Euphausia krohnii and Nematoscelis megalops in North Atlantic slop water. Limnol. Oceanogr., 31:1346-1352.

BURTON, R. S. 1983. Protein polymorphisms and genetic differentiation of marine invertebrate populations. Mar. Biol. Letts, 4:193-206.

FAO. 1985. FAO species identification sheets for fishery purposes. Southern Ocean. CCAMLR Convention area, fishing areas 48,58 and 88 . Commission for the Conservation of Antarctic Marine Living Resources. Rome, Food and Agriculture Organization of the United Nations. 232p.

FERGUSON, A. 1980. Biochemical systematic and evolution. Glasgow, Blackie. 194p.

FEVOLDEN, S. E. 1979. Investigations on krill (Euphausiacea) sampled during the Norwegian Antarctic Research Expedition, 1976 - 1977. Sarsia, 64:189-198.

1986. Genetic variation of Euphausia superba Dana in the Antarctic Peninsula waters. Sarsia, 71:169-175.

1988. Biochemical genetics and population structure of Euphausia superba. Comp. Biochem. Physiol., 90B:507 - 513.

\& AYALA, F. J. 1981. Enzyme polymorphism in Antarctic krill (Euphausiacea): genetic variation between populations and species. Sarsia, 66:167-181.

\& GEORGE, R. Y.1984. Size frequency pattern of Euphausia superba in the Antarctic Peninsula waters in the Austral Summer of 1983. J. crustacean Biol., 4 (Spec. No. 1):107- 122.

\& SCHNEPPENHEIM, R. 1989.

Genetic homogeneity of krill (Euphausia superba Dana) in the Southern Ocean. Polar Biol., 9:533 -539 . 
FLOWERDEW, M. W. \& CRISP, D. J. 1975. Esterase heterogeneity and an investigation into racial differences in the cirripede Balanus balanoides using acrylamide gel electrophoresis. Mar. Biol., 33:33-39.

FUJIO, Y.; YAMANAKA, R. \& SMITH, J. P. 1983. Genetic variation in marine molluscs. Bull. japan. Soc. scient. Fish., 49:1809-1817.

GODLEWSKA, M. \& RAKUSA-SUSZCZEWSKI, S. 1988. Variability of krill, Euphausia superba, Dana 1852 (Crustacea, Euphausiacea), distribution and biomass in the Western Antarctica (Bransfield Strait, Drake Passage, Elephant Island) during 1976-1977. Investigacion pesq., Barcelona, 52:575-586.

HUBBY, J. L. \& LEWONTIN, R. C. 1966. A molecular approach to the study of genic heterozigosity in natural populations. $I$. The number of alleles at different loci in Drosophila pseudoobscura. Genetics, 54:577-594.

KANDA, K.; TAKAGI, K. \& SEKI, Y. 1982. Movement of the larger swarms of Antarctic krill Euphausia superba population off Enderby Land during 1976 - 1977 season. J. Tokyo Univ. Fish., 68:25-42.

KALINOWSKI, J. \& WITEK, Z. 1985. Scheme for classifying aggregations of Antarctic krill. BIOMASS Handb., (27), 9p.

KATSURAGAWA, M.; NONATO, L. V.; MADUREIRA, L.; AMARAL, J. C. \& FERREIRA, S. L. B. L. 1989. Analysis of krill distribution in the Bransfield Strait and Drake Passage by means of hydroacoustic survey. Pesq. antárt. brasil., 1:11-23.

KÜHL, S. \& SCHNEPPENHEIM, R. 1986. Electrophoretic investigations of genetic variation in two krill species Euphausia superba and $E$. crystallorophias (Euphausiidae). Polar Biol., 6:17-23.

LI, C. C. 1955 . Population genetics. Chicago, University of Chicago Press. 366p.

LUBIMOVA, T. G.; MAKAROV, R. R.; MASLENNIKOV, V. V.; SHEVTSOV, V. V. \& SHUST, K. V. 1982. The ecological peculiarities, stocks and rôle of E. superba in the trophic structure of the Antarctic ecosystem. Selected Papers Presented to the Scientific Committee of CCAMLR, 1982-1984. Part II: p. 391-505. Hobart, Australia.
MacDONALD, C. M. \& SCHNEPPENHEIM, R. 1983. Breeding structure and stock identity in the Antarctic krill Euphausia superba Dana. In: Schnack, S. B., ed. On the biology of krill Euphausia superba. Proceedings of the Seminar and Report of the Krill Ecology Group. Bremerhaven, 12-16 May 1983. Ber. Polarfors. Alfred-Wegener-Inst. Polarfors., Sonderheft, 4:240-245.

; WILLIAMS, R. \& ADAMS, M. 1986. Genetic variation and population structure of krill (Euphausia superba Dana) from the Prydz Bay region of Antarctic waters. Polar Biol., 6:233-236.

MacKINTOSH, N. A. 1972. Life cycle of Antarctic krill in relation to ice and water conditions. 'Discovery' Repts, 36:1-94.

1973. Distribution of post-larval krill in the Antarctic. 'Discovery' Repts, 36:95-156.

MAKAROV, R. R. 1974. Dominance of larval forms in Euphausiid (Crustacea: Eucaridae) ontogenesis. Mar. Biol., 27:93-99.

; MASLENNIKOV, V. V.; SOLYANKIN, E. V.; SPIRIDONOV, V. A. \& YAKOVLEV, V.N.1987. Variability in population density of Antarctic krill in the western Scotia Sea in relation to hydrological conditions. In: Sahrhage, D., ed. Antarctic Ocean and resources variability. Berlin, Springer-Verlag. p. 231-236.

MARR, J. W.S. 1962. The natural history and geography of the Antarctic krill (Euphausia superba Dana). 'Discovery' Repts, 32:33-464.

MASLENNIKOV, V. V. \& SOLYANKIN, E. V. 1987. Patterns of fluctuations in the hydrological conditions of the Antarctic and their effect on the distribution of Antarctic krill. In: Sahrhage, D., ed. Antarctic Ocean and resources variability. Berlin, Springer-Verlag. p. 209-213.

MAUCHLINE, J. 1982. Key for the identification of Antarctic euphausiids. BIOMASS Handb., (5),4p.

NEI, M. 1972. Genetic distance between populations. Am. naturalist, 106:283-292.

1977. F-statistics and analysis of gene diversity in subdivided populations. Ann. Human Genet., 41:225-233.

PHAN, V. N. 1980. Estudo bioquímico e fisiológico sobre os bagres marinhos do Brasil. I. Sobre padrão eletroforético do plasma em gel de poliacrilamida dos bagres da regiảo estuarino lagunar de Cananéia. Bolm Inst. oceanogr., S Paulo, 29:301-303. 
PHAN, V. N.; GOMES, V.; SUZUKI, H. \& PASSOS, M. J. A. C. R. 1989. Preliminary study on chromosomes of Antarctic krill, Euphausia superba Dana. Polar Biol., 10:149-150.

PRIDDLE, J.; CROXALL, J. P.; EVERSON, I.; HEYWOOD, R. B.; MURPHY, E. J.; PRINCE, P. A. \& SEAR, C. B. 1987. Large-scale fluctuations in distribution and abundance of krill. A discussion of possible causes. In: Sahrhage, D., ed. Antarctic Ocean and resources variability. Berlin, Springer-Verlag. p. 169-182.

RAKUSA-SUSZCZEWSKI, S. 1978. Environmental conditions within krill swarms. Pol. Arch. Hydrobiol., 25:585-587.

ROHLF, F. J. 1988. NTSYS-pc Numerical taxonomy and multivariate analysis system. New York. Exeter Publ. 156p.

SCHELTEMA, R. S. 1971. Larval dispersal as a means of genetic exchange between geographically separated populations of shoalwater benthic marine gastropods. Biol. Bull. mar. biol. Lab., Woods Hole, 140:284-322.

SCHNEPPENHEIM, R. \& MacDONALD, C. M. 1984. Genetic variation and population structure of krill (Euphausia superba) in the Atlantic sector of Antarctic waters and off the Antarctic Peninsula. Polar Biol., 3:19-28.

SCOPES, R. K. 1968. Methods for starch gel electrophoresis of sarcoplasmic proteins. An investigation of the relative variety of species. Biochem. J., 107:139-150.

SIEGEL, V. 1983. Population structure of Euphausia superba in the eastern part of the Bransfield Strait. In: Schnack, S. B., ed. On the biology of krill Euphausia superba. Proceeding of the Seminar and Report of the Krill Ecology Group. Bremerhaven, 12-16. May 1983. Ber. Polarfors. Alfred-Wegener-Inst. Polarfors., Sonderheft, 4:227-238.

SMITH, P. J.; FRANCIS, R. I. C. C. \& JAMIESON, A. 1981. An excess of homozygotes at a serum esterase locus in the Atlantic mackerel Scomber scombrus. Anim. Blood Groups and Biochemical Genetics, 12:171-180.
SNEATH, P. H. \& SOKAL, R. R. 1973. Numerical taxonomy. San Francisco, W. H. Freeman. 573p.

SWOFFORD, D. L. \& SELANDER, R. B. 1981. BIOSYS-1: a FORTRAN program for the comprehensive analysis of electrophoretic data in population genetics and systematics. J. Hered., 72:282-283.

UTTER, F.; AEBERSOLD, P. \& WINAS, G. 1986. Interpreting genetic variation detected by electrophoresis. In: Ryman, N. \& Utter, F., eds Population genetics \& fisheries management. Washington Sea Grant Program. Seattle, University of Washington Press. p. 21- 45.

WOLNOMIEJSKI, N.; CZYKIETA, H.; STEPNIK, $R$. \& JACKOWSKA, H. 1982. Biological characteristics of Euphausia superba Dana in the southern Drake Passage and the Bransfield Strait in February-March, 1981 (BIOMASS-FIBEX). Pol. Polar Res., 3:259-271.

WORKMAN, P. L. \& NISWANDER, J. D. 1970. Population studies on southwestern Indian tribes. II. Local genetic differentiation in the Papago. Am. J. Human Genet., 22:24-49.

WRIGHT, S. 1965. The interpretation of population structure by F-statistics with special regard to systems of mating. Evolution, 19:395-420.

1978. Evolution and the genetics of populations. Variability within and among natural populations. Chicago, University of Chicago Press. v.4.

YABU, H. \& KAWAMURA, A. 1984. Chromosomes of Euphausia superba Dana. Bull. Plankt. Soc. Japan, 31:61-63.

(Manuscrito recebido 25 agosto 1992; revisto 13 dezembro 1993; aceito 17 dezembro 1993) 